\title{
PRODUÇÃO DE XILANASE POR FUNGOS FILAMENTOSOS ISOLADOS DO SOLO DA ESTAÇÃO ECOLÓGICA DE JURÉIA-ITATINS, SP, BRASIL
}

\section{XYLANASE PRODUCTION BY FILAMENTOUS FUNGI ISOLATED FROM SOIL OF THE ECOLOGICAL STATION OF JURÉIA-ITATINS, SP, BRAZIL}

\section{Ruegger, M. J. S. ${ }^{1}$ and Tauk-Tornisielo, S. M. ${ }^{2}$}

1,2 Centro de Estudos Ambientais - CEA, Universidade Estadual Paulista - UNESP, Av. 24-A, 1515, CEP 13506-900, Rio Claro, SP, Brasil; Fone/Fax: (0xx19) 534-0122; Email: mruegger@hotmail.com

\section{RESUMO}

Os fungos vêm despertando crescentes interesses em virtude de elaborarem compostos economicamente importantes, tais como: alimentos, solventes, enzimas, vitaminas, antibióticos, ácidos graxos, dentre outros produtos, justificando sua aplicação biotecnológica. Estudos da potencialidade de espécies pertencentes as regiões ainda pouco exploradas devem ser incentivadas, como é o caso da Estação Ecológica de JuréiaItatins (EEJI), SP, Brasil, onde há enorme biodiversidade, porém em parte ainda desconhecida. Desta forma, o presente estudo apresenta resultados preliminares da atividade enzimática da xilanase (E.C. 3.2.1.8) que foi avaliada em oitenta linhagens de fungos isolados do solo da EEJI, na região do Banhado Grande. Os fungos foram cultivados em farelo de trigo por quatro dias a $25^{\circ} \mathrm{C}$. As enzimas liberadas no meio de cultura foram extraídas com $30 \mathrm{ml}$ de água gelada e a atividade da xilanase foi avaliada em unidades internacionais (UI) de enzima necessária para liberar um $\mathrm{m}$ mol de xilose por mililitro por minuto, nas condições do ensaio. A melhor atividade da xilanase (1.219,8 $\left.\mathrm{UI} \mathrm{g}^{-1}\right)$ foi obtida utilizando-se Trichoderma inhamatum I.

Palavras chaves: Atividade da xilanase, fungos filamentosos, Estação Ecológica, Trichoderma inhamatum. 


\section{ABSTRACT}

The fungi constitutes a large group of organisms that presents a increasing interest relative to their potential in the development of highly important compounds, as: food, solvents, enzymes, vitamins, antibiotics, fatty acids and other products. The xylanase activity (E.C. 3.2.1.8) was evaluated in eighty filamentous fungi strains, isolated from the soil of Juréia-Itatins Ecological Station, SP, Brazil. These fungi were cultivated on wheat bran medium for four days at $25^{\circ} \mathrm{C}$. The enzymes liberated in the culture medium were extracted with $30 \mathrm{ml}$ of cold distilled water. Enzyme production was expressed as enzyme international units, and one unit of enzyme activity is defined as one $\mathrm{m}$ mol xylose released per minute per milliliter of culture extract. The best xylanase activity $\left(1,219.8 \mathrm{IU} \mathrm{g}^{-1}\right)$ was obtained with Trichoderma inhamatum strain I.

Key words: Xylanase activity, filamentous fungi, Ecological Station, Trichoderma inhamatum.

\section{INTRODUÇÃO}

As hemiceluloses são os polissacarídeos não celulósicos mais abundantes encontrados na natureza, ocorrendo nas paredes celulares das plantas, dispostas entre celulose e lignina. São constituídas por polímeros lineares ou ramificados, contendo de dois a seis diferentes açúcares ou seus derivados. Devido a esta heterogeneidade estrutural, existem diferenças entre a composição das hemiceluloses nas diferentes plantas (MOORE-LANDECKER, 1996). Para uma completa e eficiente degradação destes compostos há necessidade de um sistema de enzimas, ainda não totalmente elucidado. Entre as enzimas mais estudadas e conhecidas, contudo, estão as xilanases, por participarem da degradação da xilana, principal hemicelulose das plantas (COUGHLAN et al., 1993).

Nas últimas décadas cresceu o interesse industrial pelas enzimas fúngicas que promovem a degradação da xilana, e por fungos produtores de xilanases extracelulares. Estes microrganismos produzem enzimas xilanolíticas acessórias que são necessárias para o branqueamento das xilanas. Em escala industrial, as xilanases são produzidas, principalmente, por Aspergillus e Trichoderma (HALTRICH et al., 1996).

$\mathrm{Na}$ indústria de papel e celulose, as enzimas xilanolíticas, quando livres de celulases, auxiliam no branqueamento da polpa facilitando a remoção da lignina, podendo ser aplicadas para modificar a polpa na formação do papel ou ainda serem utilizadas na reciclagem do papel (BIELY, 1993). Estas enzimas, em associação com celulases, podem ser utilizadas para remover as paredes das células vegetais e desta 
forma, aprimorar o processo de extração de óleos vegetais. Podem também ser utilizadas na produção de sucos de frutas, na clarificação de sucos e vinhos, na fabricação de café solúvel, na liberação do conteúdo celular para produção de várias substâncias, na produção de protoplastos para uso em engenharia genética, no aumento do teor nutricional da silagem, no melhoramento da re-hidratação de vegetais secos e dar textura aos derivados lácteos (WONG e SADDLER, 1992; TEUNISSEN e CAMP, 1993).

Torna-se importante salientar os benefícios que o conhecimento de novas linhagens de fungos com potencial de aplicação biotecnológica podem oferecer. A Estação Ecológica de Juréia-Itatins, SP, transformada em patrimônio da humanidade, abriga uma diversidade interessante de ecossistemas e dentre eles encontra-se a Mata Atlântica, local onde ocorrem os fungos, dentre outros microrganismos, e de onde aqueles vêm sendo isolados do solo e têm sido analisados (ATTILI, 1994; GARLIPP, 1995; TAUK-TORNISIELO et al., 2000). Os estudos destes fungos vêm atender as atuais necessidades tecnológicas na busca de organismos que apresentem características ímpares, devido ao genoma singular que apresentam e com habilidades desejáveis sob o ponto de vista industrial e farmacológico.

O objetivo deste presente estudo foi verificar o potencial de produção da xilanase por fungos isolados do solo da Estação Ecológica de Juréia-Itatins, SP, a qual vem sendo conservada ambientalmente.

\section{MATERIAIS E MÉTODOS}

\section{Procedência das linhagens de fungos}

Foram estudadas 80 linhagens de fungos filamentosos, pertencentes a 47 espécies e 19 gêneros, isoladas do solo ( 0 a $15 \mathrm{~cm}$ de profundidade) da Estação Ecológica de Juréia-Itatins, São Paulo, Brasil e identificadas por Garlipp (1995). Os fungos vêm sendo mantidos em tubos de cultura, em ágar extrato de malte, segundo Smith e Onions (1983), a $4^{\circ} \mathrm{C}$, no laboratório do Centro de Estudos Ambientais (CEA), UNESP, Rio Claro. Os fungos foram isolados de solos da mata primária e da secundária em diferentes meios de cultura e $\mathrm{pH}$. As linhagens que foram isoladas de ambas áreas de estudo e aqui utilizadas são: Aspergillus sp; Aspergillus niger van Tieghem; Chloridium virescens (van Beyma) W. Gams \& Hol.-Jech.; Gliocladium roseum Bainier; Mucor hiemalis Wehmer; Paecilomyces carneus (Duché \& Heim.) A. H. S. Br. \& G. Sm.; Penicillium citrinum Thom; Penicillium fellutanum Biourge; Penicillium janthinellum Biourge; Penicillium nigricans Zaleski; Penicillium purpurogenum Stoll; Penicillium rugulosum Thom; Penicillium sclerotiorum van Beyma; Penicillium simplicissimum (Oudem.) Thom; Penicillium spinulosum Thom; Penicillium verruculosum Peyronel; Trichoderma hamatum (Bonord.) Bainier; Trichoderma harzianum Rifai; Trichoderma inhamatum 
Veerkamp \& W. Gams; Trichoderma koningii Oudem.; Trichoderma pseudokoningii Rifai; e, Trichoderma viride Pers. ex Gray. Os fungos aqui estudados e que foram exclusivos de solo da mata primária da Estação Ecológica são: Doratomyces stemonitis (Pers. ex Steud.) Morton \& G. Sm.; Gliocephalotrichum simplex (J. Meyer) Wiley \& Simmons; Gliocladium nigrovirens; Penicillium aculeatum Raper \& Fennell; Penicillium corylophilum Dierckx; Penicillium funiculosum Thom; Penicillium glabrum (Wehmer) Westling; Penicillium variabile Sopp; Pestalotiopsis pauciseta (Sacc.) Y. X. Chen; Scopulariopsis carbonaria Morton \& G. Smith; e, Verticillium lecanii (Zimm.) Viégas. Os fungos exclusivos do solo da mata secundária da Estação Ecológica e aqui usados são: Aspergillus wentii Wehmer; Chalara paradoxa (de Seynes) Sacc.; Chaunopycnis alba W. Gams; Cladosporium cladosporioides (Fresen.) de Vries; Colletotrichum sp; Cylindrocladium clavatum Hodges \& May; Metarhizium anisopliae var. anisopliae (Metschn.) Sorokin; Myrothecium roridum Tode ex Steudel; Penicillium sp; Penicillium decumbens Thom; Penicillium herquei Bain. \& Sartory; Penicillium miczynskii Zaleski; Penicillium oxalicum Currie \& Thom; e, Trichoderma longibrachiatum Rifai.

Estas linhagens foram isoladas segundo os diferentes meios de cultura e $\mathrm{pH}$ utilizados, de acordo com o demonstrado na Tabela 1.

TABELA 1. Meios de cultura utilizados para isolamento de fungos filamentosos de solo da Estação Ecológica da Juréia-Itatins, SP.

\begin{tabular}{|c|c|c|}
\hline \multirow{2}{*}{$\begin{array}{l}\text { Meios } \\
\text { de } \\
\text { cultura }\end{array}$} & pH & Linhagens isoladas \\
\hline & 4,0 & $\begin{array}{l}\text { Aspergillus sp; C. paradoxa; } \text { M. anisopliae; M. roridum III; } \\
\text { Penicillium sp; P. citrinum I; P. fellutanum II; P. } \\
\text { janczewskii II; P. purpurogenum II; P. simplicissimum I, II } \\
\text { e III; P. verruculosum II; P. pauciseta; T. hamatum II; T. } \\
\text { harzianum III; T. koningii I e T. viride II. }\end{array}$ \\
\hline \multirow[t]{3}{*}{ BDA } & 7,2 & $\begin{array}{l}\text { A. niger; } C . \text { clavatum; G. nigrovirens; G. roseum I; } P . \\
\text { aculeatum; } P . \text { decumbens; } P . \text { glabrum } \mathrm{II} ; P . \text { herquei; } P \text {. } \\
\text { janczewskii I; P. janthinellum; P. sclerotiorum I, II e III e } T . \\
\text { harzianum I. }\end{array}$ \\
\hline & 9,5 & $\begin{array}{l}\text { C. alba; Colletotrichum sp; D. stemonitis; } \text { M. hiemalis; } P \text {. } \\
\text { spinulosum II; P. carneus II; P. fellutanum I; } P . \\
\text { funiculosum; P. miczynskii; P. simplicissimum IV e } T \text {. } \\
\text { longibrachiatum. }\end{array}$ \\
\hline & 4,0 & $\begin{array}{l}\text { A. wentii; } C \text {. virescens } \text { II; } M \text {. roridum } \mathrm{II} ; P \text {. carneus } \mathrm{III} ; P \text {. } \\
\text { purpurogenum I e III; T. harzianum VI; } T \text {. pseudokoningii } \\
\text { II e } T \text {. viride I. }\end{array}$ \\
\hline
\end{tabular}




\begin{tabular}{|c|c|c|}
\hline \multirow[t]{2}{*}{ MA } & 7,2 & M. roridum I, $P$. carneus I e $T$. harzianum V. \\
\hline & 9,5 & $\begin{array}{l}\text { C. cladosporioides; } \quad \text { C. virescens } \mathrm{I} ; \quad G . \quad \text { simplex; } P . \\
\text { corylophilum; } P . \quad \text { oxalicum; } P . \quad \text { rugulosum; } P . \\
\text { simplicissimum } \mathrm{V} ; \text { P. variabile I; T. hamatum I; T. koningii } \\
\text { III e T. pseudokoningii I. }\end{array}$ \\
\hline & 4,0 & $\begin{array}{l}P . \text { glabrum I; } P \text {. variabile II; } S \text {. carbonaria; } T \text {. inhamatum I } \\
\text { e II e T. koningii II. }\end{array}$ \\
\hline \multirow[t]{2}{*}{$\mathrm{AO}$} & 7,2 & G. roseum II; P. janczewskii III e T. harzianum II \\
\hline & 9,5 & $\begin{array}{l}P . \text { citrinum II; } P \text {. spinulosum I; } P \text {. verruculosum I; } T \text {. } \\
\text { harzianum IV e } V \text {. lecannii. }\end{array}$ \\
\hline
\end{tabular}

Legenda: $\mathrm{BDA}=$ Ágar batata-dextrose; $\mathrm{MA}=$ Ágar malte; $\mathrm{OA}=$ Ágar aveia.

\section{Condições de cultura}

A partir de colônias crescidas em ágar extrato de malte durante 7 dias a $25^{\circ} \mathrm{C}$, foram preparadas suspensões de $1.10^{7}$ esporos $\mathrm{ml}^{-1}$ em solução de Tween 80 a $0,1 \%$. Os frascos Erlenmeyers de $125 \mathrm{ml}$ contendo meio de farelo de trigo composto de $5,0 \mathrm{~g}$ de farelo de trigo e 5,0 $\mathrm{ml}$ de água de torneira (YOSHIOKA et al., 1981), foram inoculados com $1,0 \mathrm{ml}$ da suspensão de esporos. Os cultivos foram realizados em duplicata e permaneceram incubados, por 4 dias a $25^{\circ} \mathrm{C}$.

\section{Considerações sobre a utilização do farelo de trigo como meio de cultura}

O farelo de trigo é um meio de cultura sólido de boa capacidade de absorção de água, de baixo custo por ser um resíduo agrícola e atua de maneira preponderante na economia do processo de produção enzimática. Soma-se a isso a economia de energia devido ao curto período de incubação, ressaltando-se que além de sua utilização como indutor para produção de enzimas xilanolíticas, possibilita a quantificação de várias atividades enzimáticas, a partir do extrato enzimático bruto.

\section{Obtenção do extrato enzimático bruto}

Após o período de incubação, foram adicionados $30 \mathrm{ml}$ de água destilada a $4^{\mathrm{O}} \mathrm{C}$. A suspensão foi homogeneizada com uma espátula e após $3 \mathrm{~h} \mathrm{a} 4^{\circ} \mathrm{C}$, o extrato bruto foi separado através de filtração em gaze e algodão, permanecendo posteriormente 
congelado, em frascos de vidro tampados e previamente rotulados, até o momento da análise (RODRIGUES, 1987).

\section{Atividade da xilanase (b -1,4-D-xilana xilanoidrolase, E.C. 3.2.1.8)}

Para cada reação enzimática foram suspendidas $50,0 \mathrm{mg}$ de xilana em $4,9 \mathrm{ml}$ de tampão acetato de sódio $0,05 \mathrm{M}, \mathrm{pH} 5,0$, em tubos de ensaio que foram incubados em banho-maria a $50^{\circ} \mathrm{C}$ por 5 min, para equilíbrio térmico. Nestes tubos adicionou-se $0,1 \mathrm{ml}$ do filtrado da cultura e, após homogeneização, uma alíquota de $1,0 \mathrm{ml}$ (branco), foi transferida para tubo de centrífuga contendo $1,0 \mathrm{ml}$ do reagente de Sumner, paralisandose a reação (MARTELLI e PANEK, 1968). Outras alíquotas foram retiradas após 10 e 20 min. Os tubos foram centrifugados por 8 min a $4.200 \mathrm{rpm}$, os sobrenadantes transferidos para outros tubos e após 5 min em banho-maria de água fervente foram rapidamente resfriados, adicionando-se a seguir $10,0 \mathrm{ml}$ de água destilada. As amostras foram homogeneizadas e as leituras das absorbâncias realizadas em espectrofotômetro da GBC, modelo Cintra 20, (1 de $540 \mathrm{~nm}$ ) contra o branco (RODRIGUES, 1987; CARMONA, 1995).

\section{Unidade de atividade enzimática}

Uma unidade internacional de atividade enzimática (UI) foi definida como sendo a quantidade de enzima necessária para produzir um mol de xilose $\mathrm{ml}^{-1} \mathrm{~min}^{-1}$, nas condições dos ensaios aqui realizados.

\section{RESULTADOS E DISCUSSÃO}

Todos os fungos filamentosos apresentaram atividade da xilanase em farelo de trigo, cujos valores variaram de 4,2 a 1.219,8 $\mathrm{UI} \mathrm{g}^{-1}$ de meio de cultura. As variações de acordo com as espécies e quanto as diferentes linhagens dentro de uma mesma espécie são apresentadas na Tabela 2.

TABELA 2. Atividade da xilanase dos fungos filamentosos isolados do solo do Banhado Grande da Estação Ecológica de Juréia-Itatins, SP, cultivados em meio de farelo de trigo, por quatro dias a $25^{\circ} \mathrm{C}$. 


\begin{tabular}{|c|c|c|c|}
\hline Fungos & $\begin{array}{l}\text { UI } \\
\mathrm{g}^{-1}\end{array}$ & Fungos & UI $g^{-1}$ \\
\hline Aspergillus sp & 72,6 & Penicillium oxalicum & 183,0 \\
\hline Aspergillus niger & 207,6 & $\begin{array}{l}\text { Penicillium } \\
\text { purpurogenum I }\end{array}$ & 130,8 \\
\hline Aspergillus wentii & 8,4 & P. purpurogenum II & 31,8 \\
\hline Chalara paradoxa & 490,8 & P. purpurogenum III & 167,4 \\
\hline Chaunopycnis Alba & 4,8 & Penicillium rugulosum & 7,2 \\
\hline Chloridium virescens I & 10,2 & Penicillium sclerotiorum I & 35,4 \\
\hline C. virescens II & 37,2 & P. sclerotiorum II & 71,4 \\
\hline $\begin{array}{l}\text { Cladosporium } \\
\text { cladosporioides }\end{array}$ & 74,4 & P. sclerotiorum III & 99,0 \\
\hline Colletotrichum sp & 16,8 & $\begin{array}{l}\text { Penicillium } \\
\text { simplicissimum I }\end{array}$ & 210,0 \\
\hline $\begin{array}{l}\text { Cylindrocladium } \\
\text { clavatum }\end{array}$ & 75,0 & P. simplicissimum II & 210,0 \\
\hline $\begin{array}{l}\text { Doratomyces } \\
\text { stemonitis }\end{array}$ & 34,2 & P. simplicissimum III & 31,8 \\
\hline $\begin{array}{l}\text { Gliocephalotrichum } \\
\text { simplex }\end{array}$ & 6,0 & P. simplicissimum IV & 382,8 \\
\hline $\begin{array}{l}\text { Gliocladium } \\
\text { nigrovirens }\end{array}$ & 33,6 & P. simplicissimum $\mathrm{V}$ & 235,2 \\
\hline Gliocladium roseum I & 203,4 & Penicillium spinulosum I & 25,8 \\
\hline G. roseum II & 263,4 & ||P. spinulosum II & 86,4 \\
\hline Metarhizium anisopliae & 106,8 & ||Penicillium variabile I & 195,6 \\
\hline Mucor hiemalis & 4,2 & P. variabile II & 12,0 \\
\hline Myrothecium roridum I & 48,0 & $\begin{array}{l}\text { Penicillium verruculosum } \\
\text { I }\end{array}$ & 99,0 \\
\hline M. roridum II & 43,8 & P. verruculosum II & 31,8 \\
\hline M. roridum III & 6,0 & Pestalotiopsis pauciseta & 102,0 \\
\hline
\end{tabular}




\begin{tabular}{|c|c|c|c|}
\hline Paecilomyces carneus I & $\mid 42,6$ & $\begin{array}{l}\text { Scopulariopsis } \\
\text { carbonaria }\end{array}$ & 29,4 \\
\hline P. carneus II & 16,2 & Trichoderma hamatum I & 84,6 \\
\hline P. carneus III & 30,6 & T. hamatum II & 59,4 \\
\hline Penicillium sp & 164,4 & Trichoderma harzianum I & 120,0 \\
\hline Penicillium aculeatum & 5,4 & T. harzianum II & 207,6 \\
\hline Penicillium citrinum I & 176,4 & T. harzianum III & 190,2 \\
\hline P. citrinum $\mathrm{II}$ & 148,2 & T. harzianum IV & 232,8 \\
\hline $\begin{array}{l}\text { Penicillium } \\
\text { corylophilum }\end{array}$ & 144,6 & T. harzianum $\mathrm{V}$ & 219,6 \\
\hline Penicillium decumbens & 134,4 & T. harzianum VI & 65,4 \\
\hline $\begin{array}{l}\text { Penicillium fellutanum } \\
\text { I }\end{array}$ & | 190,2 & Trichoderma inhamatum I & $1.219,8$ \\
\hline P. fellutanum II & 187,8 & T. inhamatum II & 161,4 \\
\hline $\begin{array}{l}\text { Penicillium } \\
\text { funiculosum }\end{array}$ & 107,4 & Trichoderma koningii I & 136,8 \\
\hline Penicillium glabrum I & 208,8 & T. koningii II & 156,0 \\
\hline P. glabrum II & 153,0 & T. koningii III & 6,6 \\
\hline Penicillium herquei & 121,2 & $\begin{array}{l}\text { Trichoderma } \\
\text { longibrachiatum }\end{array}$ & 204,6 \\
\hline $\begin{array}{l}\text { Penicillium janczewskii } \\
\text { I }\end{array}$ & $\mid 144,0$ & $\begin{array}{l}\text { Trichoderma } \\
\text { pseudokoningii I }\end{array}$ & 158,4 \\
\hline P. janczewskii II & 167,4 & T. pseudokoningii II & 224,4 \\
\hline P. janczewskii III & 117,6 & Trichoderma viride I & 536,4 \\
\hline $\begin{array}{l}\text { Penicillium } \\
\text { janthinellum }\end{array}$ & 97,8 & T. viride II & 233,4 \\
\hline Penicillium miczynskii & 120,6 & Verticillium lecannii & 121,8 \\
\hline
\end{tabular}

Legenda: UI $\mathrm{g}^{-1}=$ média das unidades de atividade da xilanase por grama de substrato. 
Os resultados obtidos, relativos à variabilidade da atividade da xilanase por um grande número de fungos, diferindo grandemente quanto a estes microrganismos, corroboraram com aqueles apresentados em estudo anterior, onde foram comparados vários resultados sobre produção de xilanases por fungos. Estes, apesar das distintas metodologias, têm suas unidades de atividade enzimática padronizadas, o que possibilita a comparação dos mesmos, variando de 0,3 a 4.839,0 UI ml ${ }^{-1}$ nos cultivos submersos e de 1,5 a $22.700,0 \mathrm{UI} \mathrm{g}^{-1}$, nos cultivos estáticos. As principais conclusões obtidas quanto as variações encontradas, referiram-se à escolha do substrato indutor, solúvel ou insolúvel, importante para uma eficiente produção enzimática; da composição do meio de cultura e de sua otimização; do tipo de cultivo, submerso ou em meio sólido; e, da metodologia de análise para quantificação da atividade enzimática. Parâmetros do processo, como $\mathrm{pH}$, temperatura e agitação, também afetaram a atividade e a produtividade enzimática nos biorreatores (HALTRICH et al., 1996).

Deve-se destacar, entretanto, que a variação dos resultados encontrada neste estudo está, provavelmente, relacionada com a grande biodiversidade fúngica existente na EEJI, devido o isolamento ter ocorrido com diferentes meios de cultura, e em três faixas distintas de $\mathrm{pH}(4,0 ; 7,2$ e 9,5), possibilitando ocorrência de espécies exclusivas para cada tipo de condição utilizada (GARLIPP, 1995).

Melhorias no processo de extração do complexo enzimático do meio de cultura podem proporcionar resultados mais atraentes, como foi demonstrada pela utilização de uma prensa hidráulica, a qual possibilitou melhores recuperações e maior homogeneidade do caldo enzimático (ROUSSOS et al., 1992). Outro fator que pode influenciar a produtividade enzimática é o veículo de extração das enzimas. Em estudo comparativo com outros veículos de extração (dados não apresentados), observou-se que C. paradoxa apresentou atividade da xilanase $9 \%$ maior, quando o extrato enzimático foi obtido com tampão acetato de sódio $0,05 \mathrm{M}, \mathrm{pH}$ 5,0 em comparação com a extração em água destilada. Este resultado pode variar de acordo com a espécie fúngica usada, pois com T. inhamatum I houve diminuição de $70 \%$ desta atividade neste tampão. Esses resultados induzem que as variações ocorrem de acordo com a natureza e a solubilização dos produtos devido ao fato de estarem ligados, em graus variáveis, com o substrato.

Nas condições utilizadas destacaram-se as linhagens de T. inhamatum I, $T$. viride I e C. paradoxa por apresentarem os maiores valores da atividade da xilanase, respectivamente, $1.219,8 ; 536,4$ e 490,8 $\mathrm{UI} \mathrm{g}^{-1}$. Estes resultados foram obtidos em meios sem nenhuma suplementação, diferentes daqueles apresentados por Haltrich et al. (1996), a partir de cultivos contendo, além de pequenas quantidades de xilana purificada como indutor, também sais minerais, fontes de nitrogênio e extrato de leveduras, além de períodos superiores a 20 dias de incubação e condições otimizadas para cada microrganismo. Os fungos que apresentaram melhores resultados serão estudados, posteriormente, com a finalidade de se obter otimização da produção e purificação da 
enzima, visando sua aplicação industrial.

\section{AGRADECIMENTOS}

À FAPESP pelo auxílio financeiro à pesquisa, processos n. 96/07574-5 e

97/11418-1 e bolsa de doutorado para o primeiro autor. À biomédica Eleni Nadai Malagutti, pelos auxílios no laboratório do Centro de Estudos Ambientais da UNESP.

\section{REFERÊNCIAS}

ATTILI, D.S. Isolamento, identificação e ecologia de fungos celulolíticos do solo da Estação Ecológica de Juréia-Itatins, SP. 1994. 148f. Tese (Doutorado em Biologia Vegetal) - Instituto de Biociências, Universidade Estadual Paulista. Rio Claro.

BIELY, P. Biochemical aspects of the production of microbial hemicellulases. In: COUGHLAN, M.P.; HAZLEWOOD, G.P. (Ed.) Hemicellulose and hemicellulases. London: Portland Press. 1993. p.29-52.

CARMONA, E.R. Produção, purificação e caracterização de xilanase de Aspergillus versicolor. 1995. 111f. Tese (Doutorado em Ciências Biológicas) - Instituto de Biociências, Universidade Estadual Paulista, Rio Claro.

COUGHLAN, M.P. et al. Enzymological aspects of microbial hemicellulases with emphasis on fungal systems. In: COUGHLAN, M.P.; HAZLEWOOD, G.P. (Ed.) Hemicellulose and hemicellulases. London: Portland Press. 1993. p.53-84.

GARLIPP, A.B. Isolamento e identificação de fungos filamentosos do solo do banhado grande, na Estação Ecológica de Juréia-Itatins, SP. 1995. 92f. Dissertação (Mestrado em Ciências Biológicas) - Instituto de Biociências, Universidade Estadual Paulista, Rio Claro.

HALTRICH, D. et al. Production of fungal xylanases. Biores. Technol., v.58, n.2, p.137$161,1996$.

MARTELLI, H.L.; PANEK, A.D. Bioquímica experimental. Rio de Janeiro: Ao Livro Técnico, 1968. 112p.

MOORE-LANDECKER, E. Fundamentals of the Fungi. 4.ed. New Jersey: Prentice Hall, 1996. 574p.

RODRIGUES, E.C. Caracterização citogenética e bioquímica do fungo celulolítico 
Humicola sp. 1987. 152f. Dissertação (Mestrado em Microbiologia Agrícola) - Escola Superior de Agricultura Luiz de Queiroz, Universidade de São Paulo, Piracicaba.

ROUSSOS, S. et al. Efficient leaching of cellulases produced by Trichoderma harzianum in solid state fermentation. Biotechnol. Techniques, v.6, n.5, p.429-432, 1992.

SMITH, D.; ONIONS, A.H.S. The preservation and maintenance of living fungi. Norwick: Page Bros, 1983. 51p.

TAUK-TORNISIELO, S.M. et al. Aphyllophorales from the Atlantic Rainforest of the Ecological Station of Juréia-Itatins, São Paulo, Brazil. Braz. J. Ecol., v.4, n.1/2, p.99$105,2000$.

TEUNISSEN, M.J.; CAMP, H.J.M.O. Anaerobic fungi and their cellulolytic and xylanolytic enzymes. Antonie Leeuwenhoek, v.63, n.1, p.63-76, 1993.

WONG, K.K.Y.; SADDLER, J.N. Trichoderma xylanases, their properties and application. Crit. Rev. Biotechnol., v.12, n.5/6, p.413-435, 1992.

YOSHIOKA, H. et al. Production and characterization of thermostable xylanase from Talaromyces byssochlamydoides YH-50. Agric. Biol. Chem., v.45, p.579-586, 1981. 